AVISO

Por no disponer de los correspondientes originales informáticos, la maquetación de este artículo difiere de la del publicado en papel. Por lo demás, los contenidos no han sufrido ninguna alteración.

Artículo publicado en el fascículo $1^{\circ}$ del tomo LXV (1997) de EMERITA, pp. 17-40

Autores: Jesús Lens Tuero y Javier Campos Daroca

\title{
LA GEOGRAFÍA DE ASIA EN EL LIBRO II DE LA BIBLIOTECA HISTÓRICA DE DIODORO DE SICILIA
}

This paper developes the «rhetorical» mode of analysis of Diodorus' work already applied by the authors to the first book of the Bibliotheca Historica (Emerita 61, 1993, pp. 137-157). This time, the varied contents and structure of the second book are also explained in terms of the set of topoi that lay down the greek ethnographical tradition. Diodorus attempts to present the extraordinary complexity of the Asian geography and population in the same coherent way as Egypt was in the first book of the Bibliotheca. In so doing, Diodorus faces the lack of geographical limits and ethnical unity of Asia and provides an coherent image of the continent based on the traditional conception of Asian monarchies and the specialization of the several ethne according to the requirements of the ethnographical topoi.

I

Los primeros libros de la Biblioteca de Diodoro han sido siempre un texto privilegiado para la detección de fuentes por parte de muchos estudiosos, convencidos de que los diversos autores de los que Diodoro ha extraído su material para los diversos países bárbaros se pueden localizar con relativa certeza en las suturas que van marcando los diversos bloques temáticos. Así la diferencia fundamental que se detecta entre los libros I y II, la del carácter monográfico del I, consagrado a Egipto, y la índole marcadamente heterogénea del segundo, consagrado a Asia, viene a corresponderse, para los defensores de tal hipótesis, con una diferencia básica en el plano de las fuentes seguidas. Diodoro, según los estudiosos de tal línea, habría seguido monográficamente la Historia Egipcia de Hecateo de Abdera para su exposición del país de los faraones ${ }^{1}$, mientras que para su historia asiática se habría ate-

* Este trabajo forma parte del Proyecto de Investigación que está desarrollando actualmente el Grupo de Trabajo «Historiografía Antigua y su influencia en la literatura española» (n 1062 PAI).

1 E. Schwartz, s.v. «Diodoros», RE V 1, 1903, col. 663-704. F. Jacoby incluye como apéndice de los fragmentos de Hecateo de Abdera (FGrHist 264 F 25) la práctica totalidad del libro I de Diodoro de Sicilia con un denso y enjundioso comentario en el volumen corres- 
J. Lens Tuero - J. CAMpos DarocA - La geografía de Asia en el libro II de la Biblioteca Histórica de Diodoro de Sicilia

nido de modo servil, sucesivamente, a las obras de Ctesias, Megástenes, Posidonio y Yambulo. Hasta hace relativamente poco tiempo atribuir a Diodoro algo de su propia obra era una actuación que precisaba de todo tipo de justificaciones. Nuestra postura se inclina hacia lo que en los estudios diodoreos se está convirtiendo en la nueva ortodoxia, representada por Chamoux y Sacks $^{2}$ (precedidos por Spoerri y Goukowsky): el reconocimiento de que hay que dejar al propio Diodoro la responsabilidad tanto de la determinación de sus objetivos como de la puesta en práctica de su método ${ }^{3}$.

Pero creemos que al mismo tiempo se ha introducido cierta confusión, en la medida en que se hace depender la importancia de la Biblioteca de la «rehabilitación» de su autor a partir del examen de los fundamentos ideológicos de su concepción de la historia; el sistema conceptual de Diodoro, según los mencionados autores, no hace más que reproducir el de la clase intelectual del período helenístico. Dicha doctrina oscurece el hecho fundamental de que la importancia de mucha de la información contenida en la Biblioteca está asegurada (por su condición de testimonio único, decisivo o simplemente notable $)^{4}$, y no depende de que las concepciones ideológicas de Diodoro sean representativas de las de la intelectualidad tardohelenística, caracterizadas con el ambiguo epígrafe de «eclécticas».

pondiente. Las tesis de Jacoby fueron desarrolladas por O. Murray, «Hecataeus of Abdera and Pharaonic Kingship», JEA 56, 1970, pp. 141-171. El trabajo de A. Burton, Diodorus Siculus. Book I. A Commentary, Leiden 1972, supuso un giro importante en la indagación de las fuentes de Diodoro. Una revisión del problema, en J. Campos Daroca, «Introducción al libro I» en J. Lens (dir.) Diodoro de Sicilia. Biblioteca Histórica. Libros I y II, Madrid 1995. Para la sección geográfica del libro I, véase J. Lens Tuero - J. Campos Daroca, «La geografía de Egipto en Diodoro de Sicilia», Emerita 61, 1993, pp.137-157, recogido en J. Lens (ed.), Estudios sobre Diodoro de Sicilia, Granada, 1994, pp. 279-299.

2 K. S. Sacks, Diodorus of Sicily and the First Century, Princeton, 1990; F. Chamoux, «Un historien mal-aimè: Diodore de Sicile», BAGB 3, 1990, pp. 243-52; id. «Introduction générale», Diodore de Sicile. Bibliothèque historique. Livre I, París, 1993, pp. vii-lxxvi.

3 W. Spoerri, Späthellenistische Berichte über Welt, Kultur und Götter. Untersuchungen zu Diodor von Sizilien, Basilea 1959; P. Goukowsky, Diodore de Sicile. Bibliothèque historique. Livre XVII, París 1976, y Diodore de Sicile. Bibliothèque historique. Livre XVIII, París 1978.

4 Como ha puesto de relieve W. Spoerri, «Diodorea», $M H$ 48, 1991, pp. 311-13.

EMERITA. Revista de Lingüística y Filología Clásica (EM) - LXV 1, 1997, pp. 17-40 
J. Lens Tuero - J. CAMpos DarocA - La geografía de Asia en el libro II de la Biblioteca Histórica de Diodoro de Sicilia

Frente a la búsqueda de fuentes, por un lado, y la reivindicación de la valía y la originalidad del siciliano, por otra, nuestra indagación atiende a los criterios que guían la composición de la Biblioteca, proceso en el que, en el marco de una opción genérica, unos objetivos, que Diodoro hace bien explícitos, guían una gigantesca operación de selección y reordenación de la rica tradición historiográfica griega en un texto de notable cohesión, cuyo discutible acierto literario no disminuye su importancia, al menos en el estado actual de nuestras fuentes.

En este sentido, hemos insistido más de una vez, siguiendo la lección fundamental de Drews ${ }^{5}$, en que el autor de la Biblioteca ha de ser estudiado como representante de una orientación particular en el seno de la historiografía grecorromana, la moralizante, que tiene su primer representante bien conocido en Jenofonte, cuya obra presenta analogías notables no sólo ideológicas sino también formales con la de Diodoro. Así la investigación reciente sobre Jenofonte ha puesto de manifiesto que, para este historiador, la importancia de los hechos reside básicamente en su valor paradigmático o ejemplar ${ }^{6}$, línea de trabajo particularmente efectiva en el caso de Diodoro que, como autor de una historia universal, no tenía como objetivo el de proporcionar una relación exhaustiva o innovadora de los hechos, sino el de presentarlos de modo que se pusiese de manifiesto la interpretación que del conjunto de la historia su autor quería extraer.

Junto a la enfatizada apelación a la función moralizante de la Biblioteca, tan pomposamente declarada en el proemio, debemos atender a la menos conspicua pero igualmente importante mención de los «aficionados a la lectura» ${ }^{7}$, que justifica buena parte de los contenidos de estos primeros libros. Así, en el libro que nos ocupa, Diodoro cierra la extensa y confusa sección sobre Arabia con la siguiente declaración: «Así pues, si nos hemos extendido

\footnotetext{
$5 \quad$ R. Drews, «Diodorus and his Sources», AJPh 83, 1962, pp. 383-392; en esta línea se sitúan los trabajos recogidos en J. Lens (ed). Estudios, cit. en nota 1.

6 Cf. P. Krafft, «Vier Beispiele des Xenophontischen in Xenophons Hellenika», RhM 110, 1967, pp. 103-50.

7 I 3,6. Semejante combinación de elementos se encuentra también en la Ciropedia de Jenofonte; cf. R. Breitenbach, s.v. «Xenophon», RE Suppl IX A, 1960, coll. 1708-9 y 17171742 (reimp. Stuttgart 1966)
}

EMERITA. Revista de Lingüística y Filología Clásica (EM) - LXV 1, 1997, pp. 17-40 
J. Lens Tuero - J. CAMpos DarocA - La geografía de Asia en el libro II de la Biblioteca Histórica de Diodoro de Sicilia

sobre Arabia y lo que allí se da, creemos con todo haber presentado muchos asuntos de interés para disfrute ( $\varphi \imath \lambda \eta \kappa$ Kö́$\left.^{\alpha}\right)$ de los amantes de la lectura ${ }^{8}$.

Al servicio de estos intereses lúdico-pedagógicos ${ }^{9}$, Diodoro elabora y ordena en su Biblioteca el abundantísimo material historiográfico disponible, de manera que el acceso al mismo sea lo más fácil e inmediato posible, cuestión nada despreciable si se tienen en cuenta las condiciones editoriales del mundo antiguo y los modos de lectura que exigían. La labor de Diodoro es en este sentido esencialmente «retórica» ${ }^{10}$, en el sentido de que su esencia no está en la indagación, sino en la elaboración de un material tópico con fines genéricamente persuasivos en una obra de conjunto que ofrezca en la medida de lo posible una impresión unitaria. En este sentido, es de notar que una de las carácterísticas fundamentales de la Biblioteca es su extraordinaria cohesión interna, cohesión que Diodoro hace explícita de manera insistente, tanto por medio de abundantes referencias cruzadas ${ }^{11}$ como a través, de las recurrentes declaraciones sobre el sentido ético de los acontecimientos y su significado para la formación moral (o meramente «cultural») de los lectores ${ }^{12}$.

8 II 54,7. Para la importancia del elemento paradoxográfico como factor de cohesión en la Biblioteca cf. M. Pavan, «La teoresi storica di Diodoro Siculo», RAL 16 (1961), esp. pp. 123-31.

9 Véase el prefacio de Justino al epítome de las Historias Filípicas de Pompeyo Trogo: ... omissis his, quae nec cognoscendi uoluptate iucunda nec exemplo erant necessaria. (Praef., 4).

10 No en el sentido un tanto banal de «embellecimiento» estilístico cuya falta han señalado algunos autores; cf. Sacks, o. cit., pp. 184-5.

11 Este aspecto ha sido estudiado por C. Rubincam, «The Organization and Composition of Diodoros' Bibliotheke», Echos du Monde Classique / Classical Views 31, n.s. 6, 1987, pp. 313-328, y «Cross-references in the Bibliotheke historike of Diodorus», Phoenix 43, 1989, pp. 39-61. La unidad textual es fiel trasunto de la unidad cósmica de la que Diodoro se siente instrumento en el campo de la historia; sobre la dimensión filosófica de la obra de Diodoro véase J. Lens, s.v. «Diodore de Sicile», en R. Goulet (ed.), Dictionnaire des Philosophes Antiques, París, 1994, pp. 786-795.

12 Sobre esta significativa regularidad véanse los trabajos de J. M ${ }^{\text {a }}$ Camacho Rojo «En torno a Diodoro de Sicilia y su concepción moralizante de la historia», EFG 2, 1986, pp. 5160, «El concepto de tyche en Diodoro de Sicilia», EFG 2, 1986, pp. 151-167 y «Actitudes del hombre frente a la tyche en la Biblioteca Histórica de Diodoro de Sicilia», EFG 2, 1986, pp. 169-191, incluídos en J. Lens (ed.), o. cit., pp. 33-116.

EMERITA. Revista de Lingüística y Filología Clásica (EM) - LXV 1, 1997, pp. 17-40 
J. Lens Tuero - J. CAMpos DarocA - La geografía de Asia en el libro II de la Biblioteca Histórica de Diodoro de Sicilia

En resumen, hemos subrayado que muchas de las dificultades que plantea la Biblioteca y que no encuentran solución en los términos en que habitualmente se aborda su interpretación (de prejuicio favorable o desfavorable hacia un país, personaje o causa, etc.) pueden ser entendidas, en cambio, desde un estudio «formal» de esta obra, atento a las dificultades de elaboración y disposición del material que a Diodoro le planteaba su condición de autor de una obra universal.

Por supuesto, Diodoro dispone ya de un modelo genérico en el que trabajar: la «Historia universal», cuyo primer representante es para nosotros Eforo de Cime ${ }^{13}$. Aunque podríamos remontarnos al modelo herodoteo, son historiadores del siglo IV a.C. ${ }^{14}$ como Eforo, Zoilo de Anfípolis, Anaxímenes de Lámpsaco, Timeo de Tauromenio e incluso Teopompo de Quíos, quienes empiezan, motivados por el volumen que adquieren las obras, a afrontar la obra histórica como problema compositivo de gran envergadura, en el que una serie de líneas maestras de gran alcance organizan estructuralmente el conjunto, y en el que el «libro» constituye el elemento compositivo básico. Es significativo que con estos autores comiencen a plantearse los problemas de «economía» compositiva, entre los que destaca, por ejemplo, el polémico principio $\kappa \alpha \tau \grave{\alpha} \gamma \varepsilon \dot{\varepsilon} v o \varsigma$ de la obra eforea, que conocemos precisamente por un discutidísimo pasaje de Diodoro ${ }^{15}$.

13 Siguiendo en esto la opinión de Polibio, Historias V 33,2 (= FGrHist 70). Véase K. Meister, Die griechische Geschichtsschreibung. Von den Anfängen bis zum Ende des Hellenismus, Stuttgart-Berlin-Köln, 1990, pp. 85-90. Sobre el tema de la historia universal, cf. A. B. Breebart, «Weltgeschichte als Thema der antiken Geschichtsschreibung», Acta Historiae Neerlandica 1, 1966, pp. 1-21 (ahora incluido en J. M. Alonso Núñez (ed.), Geschichtsbild und Geschichtsdenken im Altertum, Darmstadt, 1991, pp. 39-62) y P. Burde, Untersuchungen zur antiken Universalgeschichte, Diss., Erlangen, 1974, p. 17 y ss.

14 W. Will, «Die griechische Geschichtsschreibung des 4. Jahrhunderts», en J. M. Alonso-Núñez, o. cit., p. 126 y ss.

$15 \mathrm{~V} 1,4$ (= FGrHist $70 \mathrm{~T} 11)$. Una revisión crítica de la abundante literatura sobre el tema puede leerse en P. Vannicelli, «L'economia delle Storie di Eforo», RFIC 115, 1987, pp. 165-191, quien propone una interpretación «polivalente» del principio genérico seguido por Eforo. Cf. tb. G. Scheppens, «Historiographical Problems in Ephorus», en Symbolae. Historiographia Antiqua. Commentationes Lovainenses in honorem Peremans, Lovaina, 1977, pp. 115 ss.; J. Lens, «Historiografía helenística» en Unidad y pluralidad en el mundo antiguo. Actas del VI CEEC, Madrid, 1983, pp. 341-7 y L. Canfora, «Le but de l'historiographie selon Diodore», en H. Verdin - G. Scheppens - E. De Keyser (edd.), 
J. Lens Tuero - J. CAMpos DarocA - La geografía de Asia en el libro II de la Biblioteca Histórica de Diodoro de Sicilia

La amplitud de contenidos que Diodoro pretende abarcar en su obra junto con el esfuerzo sintético que en ella desarrolla hacen del problema compositivo una cuestión de primer orden en la labor de Diodoro. En este sentido la Biblioteca se construye según una serie de líneas maestras que articulan el conjunto con notable claridad tomando como unidad el libro. Diodoro distingue los primeros seis libros de acuerdo con un criterio «narrativo» que le permite distinguir las narraciones míticas de las históricas ${ }^{16}$. Dentro de esta sección propone una segunda división interna conforme esta vez a un criterio antropológico: bárbaros versus griegos ${ }^{17}$. Esta articulación en tres y tres libros para el conjunto no oculta la profunda unidad del mismo dentro de la Biblioteca que se refleja en la dominancia del factor geográfico-etnográfico en la organización de los contenidos (a falta de una cronología fiable) ${ }^{18}$, en el uso de procedimientos específicos de cohesión interna ${ }^{19}$, y en la recurren

Purposes of History. Studies in Greek Historiography from the 4th to the 2nd Centuries B.C., Lovaina, 1990, pp. 312-22.

16 La cesura mito / historia es una de las más polémicas en el debate sobre la naturaleza de la historiografía antigua. En general véase A. E. Wardman, «Myth in Greek Historiography», Historia 9, 1960, pp. 403-13, quien distingue dos formas de recepción del mito en la historiografía antigua: como digresión o bien como única vía de acceso a la historia antigua de los diferentes pueblos. Que los antiguos no enjuician el mito según un criterio de verdad, sino más bien «pragmático», ha sido destacado por C. Calame, «'Mythe' et 'rite' en Grèce: des categories indigènes?» Kernos 4, 1991, pp. 205-217 y ya antes por P. Veyne, Les Grecs ont eux cru à leur mythes?, París, 1983 (hay traducción española, Buenos Aires, 1987). En este sentido, la posición de Diodoro es ejemplar: el mito es, ante todo, historia antigua, pero tiene además un importante valor moral en tanto que ejemplifica, como el resto de la historia, la pervivencia de las acciones virtuosas (cf. las polémicas declaraciones que abren el libro IV esp. 1.4-5). Sobre el lugar del mito en los primeros libros de la Biblioteca véase $\mathrm{M}$. Sartori, «Storia, 'utopia' e mito nei primi libri della Bibliotheca historica di Diodoro Siculo», Athenaeum 61, 1984, pp. 492-507, esp. pp. 520-29, quien destaca la originalidad diodorea de tomar partido decidido por la recuperación para la historia del pasado mítico dándole un lugar relevante en la organización de la obra.

17 Como se ve, los bárbaros quedan «recluídos» en el ámbito del mito, mientras que los griegos protagonizan el paso del mito a la historia, en un proceso cuya formulación más clara remonta a Tucídides, para quien los bárbaros de hoy viven como los griegos de antes (I 5.5).

18 I 5.1

19 Cf. Rubincam, «Cross-references...», art. cit., p. 39, donde destaca el hecho significativo de que para la primera sección de la Biblioteca (libros I-VI), las formas de referencia cruzada utilizadas por Diodoro se asemejan sobre todo a las que utiliza Plinio en su 
J. Lens TUero - J. CAMPos DARocA - La geografía de Asia en el libro II de la Biblioteca Histórica de Diodoro de Sicilia

cia de una serie de motivos narrativos que han sido estudiados por Sartori en el trabajo antes citado.

Finalmente, los tres primeros libros dedicados al mundo no griego obedecen de forma monográfica a una dominante geográfica, según la cual se pueden distinguir con nitidez una serie de partes «naturales» del ecumene: Egipto, Asia y Libia ${ }^{20}$. El ámbito geográfico cubierto por los pueblos bárbaros es predominantemente el meridional-oriental. Los tres primeros libros constituyen pues una unidad geográfica que recorre toda la zona «bárbara» del ecumene, tomando como eje la siempre ambigua tierra de Egipto, referencia recurrente en uno y otro libro, y cubriendo el libro II todo el este, y el III, el resto de la zona meridional. Se observará que el criterio geográfico, aparentemente el más objetivo, se encuentra sobredeterminado por los criterios que hemos llamado «narrativo»y «antropológico», siguiendo una concepción cualitativa que ha guiado la práctica totalidad de la indagación geográfica y etnográfica en el mundo antiguo ${ }^{21}$.

Al situar la Biblioteca dentro de unas coordenadas literarias específicas, la de la historiografía moralizante, por un lado, y la de la síntesis enciclopédica de un material muy amplio, por otro, estaremos con frecuencia en condiciones de determinar los aspectos originales de la actuación de Diodoro. Esta originalidad puede comportar actuaciones positivas, que permitan rei-

Historia Natural (p. 39). Otros paralelos pueden derivarse del estudio de la arquitectura de ambas obras; cf. para Plinio cf. S. Sconocchia, «La structure de la $N H$ dans la tradition scientifique et encyclopédique romaine» en Pline L'ancien. Témoin de son temps. Conuentus Pliniani Internationalis Namneti 22-26 Oct. 1985 habiti, ed. cur. I. Pigealdus \& I. Orozius, Salamanca-Nantes, 1987, pp. 623-632.

20 Sobre el reencuentro de la geografía y la historia en los historiadores del siglo IV ha escrito elocuentemente S. Mazzarino, Il pensiero storico classico, vol. II, Roma-Bari, 1983, p. 43 y ss.

${ }^{21}$ Como han puesto de relieve los estudios de P. Janni, en especial «Il mondo della qualità», AION 33, 1973, pp. 445-400 y 35, 1975, pp. 146-177. En este sentido ya había avanzado A. Dihle con su trabajo «Der fruchtbare Osten», RhM 105, 1962, pp. 97-110 (recogido en A. Dihle, Antike und Orient. Gesammelte Aufsätze, Heidelberg, 1984. pp. 4760). Para la importancia de estas ideas en la tradición historiográfica moderna véase el artículo de J. Lens, «Bartolomé de las Casas y la historiografía moderna», en M. A. Marcos Casquero (coord.), Estudios de tradición clásica y humanística (VII Jornadas de Filología Clásica de las Universidades de Castilla y León), León, Universidad, 1993, pp. 87-104. 
J. Lens Tuero - J. CAMpos DarocA - La geografía de Asia en el libro II de la Biblioteca Histórica de Diodoro de Sicilia

vindicar la personalidad del autor de Agiro como historiador, pero hemos de estar también dispuestos a aceptar sus aspectos negativos y, de modo especial, a determinar sus características técnicas a la hora de seleccionar y jerarquizar el ingente material que tenía a su disposición. A esta toma de postura no nos lleva únicamente el deseo de «reivindicar» a Diodoro, sino, fundamentalmente, el de alcanzar un conocimiento más depurado de los historiadores perdidos de los que él da conocimiento y noticia.

Nuestro propósito en este trabajo es dar un paso más en esta línea, estudiando la geografía de Asia tal y como la presenta el libro II no sólo como punto de partida para determinar las fuentes, sino como la clave para el problema compositivo que plantea la redacción de un libro monográfico sobre Asia en el seno de un conjunto guiado por las exigencias de equilibrio y simetría. En el libro II la cuestión es especialmente interesante porque en este caso no nos encontramos con una sección geográfica diferenciada, como era el caso en la historia egipcia, sino que la imagen de Asia es sobreentendida; la geografía de Asia funciona como un «presupuesto», a partir del cual elementos diversos cobran un sentido unitario. De este modo una reflexión atenta sobre la profunda imbricación de la geografía en la historia en el libro II nos permite extraer ciertas conclusiones de carácter general acerca del método de trabajo de Diodoro. Como resultado creemos poder demostrar que existe entre los dos primeros libros de esta obra un paralelismo notable que ha de ser atribuído al trabajo personal de nuestro historiador en el seno de la tradición historiográfica precedente.

\section{II}

Cuando Diodoro resume el tema del libro segundo de su Biblioteca como la «historia antigua de Asia» ${ }^{22}$ entiende que el continente asiático permite dotar al libro de una unidad semejante a la que presenta el libro primero, dedicado monográficamente a Egipto y al tercero, que ocupa la descripción de los pueblos meridionales. Ahora bien, Egipto respondía de manera ejemplar a ese tratamiento monográfico, mientras que en el caso de Asia nos encontramos con una situación mucho más problemática: por la notable fluidez $\mathrm{e}$

\footnotetext{
22 II $1,3$.
} 
J. Lens Tuero - J. CAMpos DarocA - La geografía de Asia en el libro II de la Biblioteca Histórica de Diodoro de Sicilia

imprecisión de los mismos límites naturales que pretenden definirlo, por la extensión de territorio -incomparablemente mayor- que delimitan y, función de lo anterior, la extraordinaria variedad étnica que puebla este territorio. Asia no tiene, pues, unidad geográfica ni étnica, por lo que Diodoro se enfrenta a un problema de envergadura cuando quiere dotar al libro II de un carácter monográfico semejante al del primer libro ${ }^{23}$.

Por un lado la configuración de Asia como unidad geográfica responde una tradición bien asentada en la que convergen experiencias históricas del mundo griego y los esfuerzos más o menos especulativos de escritores y sabios. El resultado ha sido esa persistente construcción polar que representa el mundo dividido en dos mitades, Asia y Europa, división cuestionada ya por primera vez en Heródoto ${ }^{24}$, pero que ha permanecido esencialmente invariable desde Hecateo de Mileto hasta Varrón ${ }^{25}$. El hecho incuestionable de que la presentación polar aparece de manera preponderante en la narración de conflictos evidencia el fundamento histórico de la división, que adquiere carta de naturaleza a través de la representación geográfica ${ }^{26}$.

23 Sobre el carácter modélico del lógos egipcio de Heródoto cf. G.Murray, «Herodotus and Hellenistic Culture», CQ 22, 1972, pp. 200-13.

24 Historias IV 36,2. Sobre el sentido y los personajes de la polémica, cf. M. R. Cataudella, «La geografia ionica, Erodoto e il Perì Hebdomadôn Pseudoippocratico, cap. 11», Sileno 13, 1987, pp. 33-57.

25 Véase sobre este tema el reciente trabajo de Gh., Ceauçescu, «Un topos de la littérature antique: l'éternelle guerre entre l'Europe et l'Asie», Latomus 50,2 (1991), 327-341, que recoge la abundantísima bibliografía al respecto.

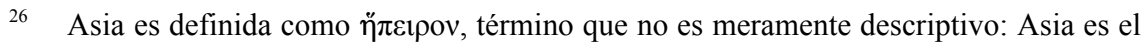
continente por antonomasia, mientras que es característico de la polis su carácter isleño; cf. S. Vilatte, «L'insularité dans la pensée grecque: au carrefour de la Géographie, de l'Ethnographie, de l'Histoire», Revue Historique, 181/1, 1989, pp. 3-13 y L'insularité dans la pensée grecque, Besançon, 1991. El vocabulario geográfico está «políticamente marcado» como se evidencia en el hecho de que la Atlántida platónica, en la que se define la naturaleza de la monarquía oriental (cf. P.Vidal Naquet, «Atenas y la Atlántida», en Formas de pensamiento y formas de sociedad en el mundo griego. El cazador negro, Barcelona, 1983, pp.304-29), es «el verdadero continente» (Timeo 25a). También era el «auténtico continente» el «otro mundo» que representaba Teopompo en el libro VIII de sus Filípicas, al que se dio el nombre de Maravillas (FGrHist 115 F 75); ese mundo no sólo era el único que merecía el nombre de continente sino que, respecto a él, Europa, Asia y Libia eran sólo islas.

EMERITA. Revista de Lingüística y Filología Clásica (EM) - LXV 1, 1997, pp. 17-40 
J. Lens Tuero - J. CAMpos DarocA - La geografía de Asia en el libro II de la Biblioteca Histórica de Diodoro de Sicilia

Pero, por otro lado, Asia tiene una caracterización cualitativa que da razón de esta distinción tan marcada. Es un tema suficiente para dar coherencia a un libro, como lo ha sido Egipto, porque el primer elemento definidor de Asia es, precisamente, la variedad inabarcable, la productividad desaforada e inagotable de formas nuevas, siempre sorprendentes, todo lo que podríamos sintetizar con el término $\pi$ oıкı $\lambda i \alpha^{27}$. Pero la exuberancia definidora de Asia en el imaginario antiguo y moderno se complementa con un segundo factor igualmente definidor: el poder despótico que unifica lo diverso en tanto que lo posee. Asia es, al menos desde Heródoto, el espacio en el que se ejerce naturalmente el poder de un monarca ${ }^{28}$. El abigarrado cuadro de la corte persa, en el que confluyen los hombres de todo el imperio con sus lenguas, vestimentas y productos, es la representación fehaciente de la unidad que irradia el poder, unico factor de cohesión entre lo absolutamente dispar. El debilitamiento del poder se corresponde con la imagen de la corrupción y la descomposición.

Diodoro se sitúa así en la historia de una idea de extraordinaria trascendencia para nuestra cultura, la de Oriente y el «orientalismo» ${ }^{29}$, conceptualizado en términos de alteridad radical, por un lado, y, por otro, de síntesis de lo diverso y simbiosis de lo contradictorio, imagen recurrente de lo extraño y lejano bajo la égida de un monarca absoluto que unifica en tanto que con-

27 Sobre esto ha insistido J. Lens, «Libro II, traducción y notas», en Diodoro de Sicilia, cit.

28 En Heródoto, la relación entre Asia y poder está planteada en términos complejos que subyacen a planteamiento trágico del conflicto ; en Historias, I 4,4 aparece «reivindicada» como espacio natural de poder para los monarcas persas por los sabios ( $\lambda$ ó 101$)$. Pero a este nómos étnico (formulado parcialmente en III 97.4), se contrapone un nómos regio, el de expandir el imperio sobrepujando al predecesor en el trono (III 134,1-4; VII 5,$1 ; 8 \mathrm{a} .1 ; 50,3)$. Sobre el lugar de la monarquía en la obra herodotea, cf. F. Hartog, Le miroir d'Hérodote. Essai sur la représentation de l'autre, París, 1980, pp. 129-185.

29 El polémico libro de Edward W. Said, Orientalismo, Madrid, 1990 (la edición original inglesa es de 1978) busca las «raíces» griegas de esta idea en la dramaturgia ateniense (sin duda por la importancia del concepto teatral de «representación» en su revisión demoledora del orientalismo), proponiendo una lectura realmente simplificadora de las Bacantes de Eurípides (cf. la propuesta más documentada de S. Saïd, «Grecs et barbares dans la tragèdie d'Euripide. La fin des différences?», Ktema 9, 1984, pp. 29-53); deja, sin embargo, al margen escritos tan reveladores en este sentido como los de los historiadores o los escritos hipocráticos.

EMERITA. Revista de Lingüística y Filología Clásica (EM) - LXV 1, 1997, pp. 17-40 
J. Lens Tuero - J. CAMpos DarocA - La geografía de Asia en el libro II de la Biblioteca Histórica de Diodoro de Sicilia

quista y dispone todo a su capricho. Lo interesante y, si se quiere, lo «original» del Asia de Diodoro es que sus intereses literarios le han llevado a enfatizar la unidad de Asia, aportando de esta manera un cuadro especialmente coherente de la misma cuya influencia está aún por valorar. Diodoro se sitúa a sí mismo en un ámbito «textual» que pretende confirmar en sus aspectos fundamentales una imagen ya existente ${ }^{30}$. De ahí que lo más sorprendente sea la simplicidad y hasta cierto punto sistematicidad con la que se inserta en ella. Para ello Diodoro no tiene en principio que realizar un gran esfuerzo; sólo dejar hablar un «discurso» sobre Asia ya constituido en la larga tradición de la que es heredero y fiel servidor.

La originalidad de Diodoro está, pues, en presentar una imagen especialmente coherente de Asia, en la medida en que revalida la tradición ya establecida sobre este continente siguiendo las exigencias de síntesis de su historia universal. Esta labor es bien visible en el orden de la disposición. El abundante material a mano es organizado de manera que redunde en la unidad del libro y para ello, es nuestra tesis, recurre al diseño tópico de la literatura etnográfica, tan claro por demás en el libro I, con el que la historiografía antigua aborda la descripción de un país o etnia determinada, y ajusta los contenidos en la medida de lo posible de manera que el cuadro resulta en buena medida homólogo del egipcio ${ }^{31}$.

III

El libro II de la Biblioteca se inicia con la historia de Asiria y Media. Asia es un espacio geográficamente complejo y étnicamente muy diverso, cuya unidad le viene dada no por unos límites naturales ni, mucho menos, por una población homogénea, como en el caso de Egipto (que tanto llama-

30 Sobre la actitud «textual» propia de Occidente ante Oriente, cf. Said, o. cit., pp. 1214.

31 F. Jacoby, «Über die Entwicklung der griechischen Historiographie und den Plan einer neuen Sammlung der griechischen Historikerfragmente», Klio 9, 1909, pp. 88-96 (recogido en Abhandlungen zur griechischen Geschichtsschreibung, Leiden, 1956, p. 26 y ss.). Pese a su gran utilidad como aglutinador del conjunto de tópoi que determinan el horizonte de intereses de los griegos sobre cualquier país extranjero, lo interesante de este modelo es que experimenta una extraordinaria capacidad de adaptación a los casos específicos.

EMERITA. Revista de Lingüística y Filología Clásica (EM) - LXV 1, 1997, pp. 17-40 
J. Lens Tuero - J. CAMpos DarocA - La geografía de Asia en el libro II de la Biblioteca Histórica de Diodoro de Sicilia

ban la atención a Diodoro), sino por la acción del poder de los monarcas que constituye su historia. Nada más natural para Diodoro, en consecuencia, que el hecho de comenzar este lógos asiático por el momento constitutivo de Asia, representado no por los primeros hombres, como en el caso de Egipto, sino, significativamente, por el primer monarca que la unifica bajo su dominio, Nino, el primer soberano que subyugó «toda el Asia que va desde el Tanáis hasta el Nilo» ${ }^{32}$. Antes de Nino habían reinado en Asia reyes locales y, tras él, los demás reyes tan sólo añaden o pierden dominios extra-asiáticos (Etiopía) o territorios que, por relación al núcleo asiático incluido entre los ríos Tanáis y Nilo, pueden ser considerados marginales y relativamente independientes: Bactria ${ }^{33}$ y, sobre todo, Arabia, India, Escitia. En realidad, en vez de límites definidos, tan llamativos en el país del Nilo, la geografía de Asia se organiza en torno a un núcleo, sobre el que el poder de los monarcas se ejerce ininterrumpidamente, y unos márgenes que varían con la historia del imperio y la capacidad de los sucesivos gobernantes. Todo el libro «asiático» secunda con su disposición este movimiento de conquista iniciado por Nino, desde un núcleo (Asiria, Media, Persia) hasta la periferia, donde un primer cinturón de países de relativa independencia deja paso a un segundo en que se diluye la autoridad en los pueblos inaccesibles del extremo norte (Hiperbóreos) y el extremo sur (islas del Sol).

En este sentido, la geografía de Asia es objeto de una extremada simplificación, que reduce la compleja realidad cultural y étnica asiática a ámbitos

32 II 2.1. Adquiere sentido en este contexto la extensa relación de regiones de Asia conquistadas por Nino en II 3-4, cuyo único paralelo en la Biblioteca es el catálogo de las satrapías a la muerte de Alejandro en el libro XVII. Diodoro hace expresa su esencial dependencia de Ctesias, quien en la enumeración de los pueblos sometidos era más prolijo, haciendo uso de una técnica expositiva destinada a crear en el lector el efecto de magnitud incomensurable de Asia y que es, desde Heródoto, tópica en la historiografía de tema oriental. Cf. Justino, I, I, 8: Domitis igitur proximis, cum accesione uirium fortior ad alios transiret et proxima quaeque uictoria instrumentum sequentis esset, totius Orientis populos subegit. G. Goosens, «L'histoire d'Assyrie de Ctesias», AC 9, 1940, p. 26 y Jacoby, «Ktesias», RE XI, col. 2052, señalan que la extensión de las conquistas de Nino en Ctesias coincide con las que el imperio persa tenía en tiempos de Artajerjes.

33 Bactria queda singularizada en el relato, frente al resto del territorio asiático, por su especial inaccesibilidad (II 2,4; 5,3).

EMERITA. Revista de Lingüística y Filología Clásica (EM) - LXV 1, 1997, pp. 17-40 
J. Lens TUero - J. CAMPos DARocA - La geografía de Asia en el libro II de la Biblioteca Histórica de Diodoro de Sicilia

caracterizados por su reconocida independencia política: India ${ }^{34}$, Escitia $^{35}$ y Arabia $^{36}$, países de los que la tradición histórica y etnográfica subrayaba precisamente su inatacabilidad ${ }^{37}$, eran, respectivamente, los límites septentrional, oriental y meridional de un territorio que es conceptuado por Diodoro como ámbito primordialmente político, sometido, en momentos diversos, al imperialismo asirio, escita y amazónico ${ }^{38}$. Nadie parece haber reparado en esta importante característica del libro II, la de que partes del mismo cuya fuente principal, presuntamente, no es la misma, coincidan en determinar un idéntico modelo de expansión para un imperialismo histórico y otros míticos. Hay todas las razones para pensar que ha de ser atribuida a Diodoro esta actuación, que no redunda precisamente en su mérito, pero nos ilustra sobre sus dificultades.

¿Qué remonta a Ctesias de esta presentación de la historia de Asia? Se trata de una cuestión ineludible, dado que Diodoro reconoce repetidamente su deuda con el historiador de Cnido y que el conjunto de la sección sobre la historia asirio-meda (II 1-34) muestra una notable coherencia que sugiere un uso masivo y directo de los Persiká de Ctesias. En un artículo dedicado a

34 La India es un territorio parcialmente sometido (II 37,3), pero en el resumen de los contenidos del libro II que Diodoro, según su práctica habitual, pone al principio del libro siguiente (III 1,2), la India aparece mencionada como un apéndice de la expansión babilonia.

35 La ambigüedad del espacio escítico entre Asia y Europa tiene un protagonismo significativo en el relato de Heródoto; cf. Hartog, o. cit., pp. 49-50.

36 La inatacabilidad de Arabia es un tópico de la Biblioteca, ya destacado por J. Lens, «La respuesta de los árabes nabateos a Demetrio Poliorcetes», EFG 2, 1986, pp. 169-191 (recogido en Estudios ..., pp. 117-125). En el libro II es de señalar que los árabes se integran voluntariamente en el imperio persa (II 1,5; 24,6); ya en Heródoto eran nación no sometida (III 88) que con todo presentaba tributos al rey (III 97,5); cf. A. Dihle, «Arabien und Indien», en Hérodote et les peuples non grecs, Entretiens sur l'antiquité classique XXV, VandoeuvresGenève, 1990, pp. 46-50.

37 Ya Jacoby había formulado una especie de «ley» historiográfica según la cual «Im allgemeinen gibt es echte Etnographien nur von Ländern, die politisch selbständig sind, und nur solange das sind», art. cit., p. 31 .

38 Las conquistas escíticas en el relato de Diodoro están marcadas por la expansión hasta el Tanáis, paso del Tanáis y llegada al Nilo como límite máximo (II 43,2; 43,4); idéntico movimiento se da en el caso de las Amazonas (II 45, 4; 46, 1-2), quienes sin embargo sólo llegan a alcanzar el territorio de Siria.

EMERITA. Revista de Lingüística y Filología Clásica (EM) - LXV 1, 1997, pp. 17-40 
J. Lens Tuero - J. CAMpos DarocA - La geografía de Asia en el libro II de la Biblioteca Histórica de Diodoro de Sicilia

este tema ${ }^{39}$, señala Bigwood algunos puntos en los que Diodoro sigue fielmente a Ctesias: la localización errónea de Nínive en el Eufrates (II 3,2) ${ }^{40}$ y la tendenciosa presentación de las opiniones de Heródoto sobre el embalsamamiento etíope (II 5,1) o la historia de Media (II 32,3-3).

Podríamos añadir igualmente, que mientras en los primeros libros de la Biblioteca la expedición de los monarcas tiene un modelo recurrente en la figura del héroe civilizador, concretada de manera paradigmática en las figuras de Dioniso, Hércules, Alejandro y, sobre todo, César, este modelo no es muy adecuado para el caso de $\mathrm{Nino}^{41}$. El horizonte de Dioniso es el oikoumene, en su propósito de hacer avanzar lo más posible la civilización; Nino y sus sucesores restringen sus miras al horizonte asiático (en marcado contraste con los monarcas herodoteos que aspiraban a hacer coincidir los límites de la tierra con los de sus dominios). Llama también la atención el hecho de que el modelo de la expedición de Alejandro no determina la narracion de la campaña de Nino del modo en que lo hace en el caso de la expedición de Sesóosis ${ }^{42}$, Dionisos ${ }^{43}$, donde el paralelo es explícito, y Hércules ${ }^{44}$. En los

39 J. M. Bigwood, «Diodorus and Ctesias», Phoenix 34, 1980, pp. 195-207.

40 Pero no esta en absoluto clara la contradicción con otros pasajes de la Biblioteca en los que Diodoro situaría correctamente Nínive junto al Tigris (XVII 53,3-4; 55,1), lo que demostraría que en este punto ha reproducido una noticia errónea de Ctesias. Cf. a este respecto la nota al pasaje en J. Lens, «Libro II. Traducción y notas», en J. Lens, Diodoro de Sicilia, ..., cit., pp. 319-20.

41 Sartori, art. cit., p. 498 y Sacks, o. cit., pp. 76-7; consideramos por tanto inadecuada la asimilación indiscrimanada de personajes regios que hace Sartori en «Note sulla datazione dei primi libri della Bibliotheca Historica di Diodoro Siculo», Athenaeum 61, 1983, p. 551. En II 5,4-6, donde Diodoro justifica las cifras astronómicas del ejército movilizado por Nino contra Bactria (pasaje que remonta con toda probabilidad al propio Diodoro) no se trae a colación el parangón de Alejandro o César, y sí el de Darío, Jerjes, Anibal, e incluso Dionisio de Siracusa, cuyas campañas están conceptuadas en términos de conquista sin asomo de acción civilizadora. Del mismo modo, lo fundamental en este comentario diodoreo es la equiparación entre el ejército de Nino y los recursos humanos de Asia en su conjunto, lo que constituye en definitiva un tópico de la presentación de los ejércitos asiáticos por los historiadores antiguos.

42 En el relato de las hazañas de Sesóosis subraya Diodoro, con una reiteración que no puede dejar de ser significativa, las pretensiones universalistas del faraón (I $53.7 ; 8 ; 9 ; 10$ ), quien supera a Alejandro por la extensión de sus conquistas (I 55.3); igualmente significativo es que Sesóosis traspase los límites de Europa y Asia (I 55.4), mientras que en el caso de 
J. Lens TUero - J. CAMPos DARocA - La geografía de Asia en el libro II de la Biblioteca Histórica de Diodoro de Sicilia

monarcas asiáticos el motivo de la expedición tiene la función de renovar con cada reinado la relación de dominio natural sobre un territorio ${ }^{45}$. Hay que tener en cuenta los actividades de transformación del paisaje operada por los reyes, especialmente en el caso de Semíramis, que difícilmente se dejan reducir a la la simple categoría de evergéticas. Las expediciones de Semíramis son decididamente erráticas; su único fin parece ser la transformación del territorio sin que exista referencia a un propósito universalista y civilizador. Es significativo en este sentido que su expedición a Etiopía venga dictada por su deseo de ver las maravillas de esa tierra (II 14.3-15) ${ }^{46}$.

Nino se explicita que sus conquistas se extienden entre el Tanáis y el Nilo. Nótese que también el paralelo Diónisos-Sesóosis tiene sus límites, dado que el segundo limita su actividad benefactora y civilizadora al ámbito de Egipto.

43 La expedición de Dioniso / Osiris tiene igualmente un talante universal (I 17.1; 19.6; 20.3), manifiesto en el traspaso de los continentes (I 19.1). Análogas pretensiones son las del Dioniso griego (IV 3.5), aunque Diodoro restringe el alcance de este viaje («casi todo el mundo habitado») en lo que sólo puede ser un esfuerzo por hacer concordar esta noticia con la que encontramos en el III 3.1, según la cual Dioniso (como tampoco Heracles) no alcanzó Etiopía.

44 La labor civilizadora de Heracles es universalmente reconocida (IV 36.1), pero no se puede decir que sea fruto de una expedición civilizadora como la de Dioniso.

45 Esta tendencia a remontar la delimitación territorial del imperio al monarca fundador de la dinastía lo podemos encontrar ya en Jenofonte. En la Ciropedia, el imperio persa no es ya el resultado de un proceso de expansión que se prolonga a lo largo de una sucesión de reyes, como es el caso de la narración herodotea, sino que se conforma ya con su fundador, que habría llevado su poder a los límites naturales de Asia. Es significativo, en este sentido, que Jenofonte atribuya a su héroe la conquista de Egipto, de modo que ya desde el mítico monarca alcanza Persia los límites de su poder, que coinciden con los de Asia: Ponto, Etiopía, Mar Rojo y Egipto (Ciropedia I 1.4; VIII 8.1; 7.20-23). Sobre esta presentación como fruto del etnocentrismo persa, cf. S.W. Hirsch, The Friendship of the Barbarians. Xenophon and the Persian Empire, Hannover-London 1985, pp. 79 sg. En cuanto a Ctesias, el resumen realizado por Focio de los Persiká, por desgracia de modo extremadamente esquemático, nos informa de que el historiador de Cnido terminaba su relato con una enumeración de trayectos, días y parasangas desde Efeso hasta Bactria y la India, y con un catálogo de los reyes desde Nino y Semíramis hasta Artajerjes (FGrHist 688 F 33). La índole original de esta recapitulación final nos lleva a pensar que la consideración casi exclusivamente políticomilitar del territorio asiático comprendido entre el Tanáis y el Nilo que encontramos en el libro II de la Biblioteca remonta en lo esencial a Ctesias; actuación propia de Diodoro sería el amplificar esta representación al caso de las monarquías escita y amazónica.

46 Sobre la contemplación propia de los monarcas persas cf. D. Konstan, «Persians, Greek

EMERITA. Revista de Lingüística y Filología Clásica (EM) - LXV 1, 1997, pp. 17-40 
J. Lens Tuero - J. CAMpos DarocA - La geografía de Asia en el libro II de la Biblioteca Histórica de Diodoro de Sicilia

Sin embargo, parece que hay que conceder que la labor de Diodoro en la redacción de estos capítulos ha sido bastante intensa. Bien podemos decir que buena parte de esta actuación se encamina a eliminar el material «marginal». La conquista de Etiopía motivaba en la obra de Ctesias un excurso en el que el médico cnidio desplegaba una vez más su polémica contra las supercherías de Heródoto; Diodoro ha desplazado este tema, con excepción de dos mirabilia ${ }^{47}$, a su lugar correspondiente en el plan de su Biblioteca ${ }^{48}$. La extremada síntesis a la que ha sido sometida la historia meda en comparación con la de Asiria se puede explicar igualmente por el mínimo papel que la primera tiene en la configuración espacial de Asia ${ }^{49}$.

El caso de Semíramis es especial, pues Diodoro, siguiendo en esto a Ctesias, ha hecho de ella el personaje eje de la historia asiria ${ }^{50}$, concretando narrativamente una de las dimensiones simbólicas de la conceptualización antigua de Asia: su carácter esencialmente femenino ${ }^{51}$. En este sentido hay que subrayar que alinearla con los demás héroes conquistadores y civilizadores

and Empire», Arethusa 22 1-2, (1987), pp. 60- 73 y J. Campos, «Saber y poder en las Historias de Heródoto», Florentia Iliberritana, 3 (1993), pp. 101-115.

47 Que tienen una función narrativa en la medida en que justifican el viaje de Semíramis a esta tierra.

48 Que no es otro sino el libro III, en el que se toca esta zona del mundo, redundando en la dominante geográfica de esta primera sección de la Biblioteca.

49 El brevísimo resumen con el que Diodoro introduce la historia del final de la hegemonía meda (II 32.2) simplifica el pasaje homólogo de Heródoto (I 95.2) en dos sentidos: redondea la cifra de los años del dominio asirio (500 frente a los 520 de Heródoto) y amplifica el dominio asirio, que en Heródoto se restringía al Asia «superior», a Asia sin más.

50 Cf. S. Mazzarino, o. cit. pp. 498 sg., quien destaca la originalidad de Ctesias en este punto con respecto a Heródoto.

51 Véase sobre este componente de la imagen de Asia J. Lens, «Introducción al libro II», cit., pp. 284 ss., donde se subraya la consistencia del tratamiento de los personajes femeninos por parte de Diodoro; cf. para la tradición orientalista, cf. Said, o. cit., pp. 50-51. Conviene sin embargo marcar las diferencias, pues mientras el orientalismo moderno que esboza Said reconoce la feminidad de Asia por su esencial pasividad, con una clara connotación sexual, lo que distingue el Asia de Diodoro es que las mujeres toman el protagonismo en la acción, punto en el que ya encontramos importantes antecedentes en Heródoto. El tema del travestismo femenino, por el que las mujeres asumen con pleno éxito los roles viriles, es esencial en la tradición ctesiana, punto en el que es muy plausible que el modelo sea la literatura dramática.

EMERITA. Revista de Lingüística y Filología Clásica (EM) - LXV 1, 1997, pp. 17-40 
J. Lens Tuero - J. CAMpos DarocA - La geografía de Asia en el libro II de la Biblioteca Histórica de Diodoro de Sicilia

no nos ayuda mucho, más bien todo lo contrario, a entender su peculiaridad en la Biblioteca de Diodoro ${ }^{52}$. Ciertamente, Semíramis, y sólamente ella, traspasa los límites asiáticos al invadir Egipto, Libia y Etiopía, pero en este capítulo del libro II Diodoro es especialmente moroso con los detalles geográficos. Antes de la expedición egipcia Semíramis ha recorrido «todos los restantes territorios sobre los que extiendía su poder en Asia» (II 14.1), dejando memoria en todo el continente de su poder (II 14.2). Por otro lado, cuando Semíramis vuelve de la campaña que la ha llevado a Etiopía y se dirige a Bactria el texto de Diodoro se ve obligado a reflejar el cambio de escenario y continente añadiendo la indicación pertinente (II 16.1), completamente innecesaria para quien sepa dónde esta Bactria ${ }^{53}$. Esta indicación didáctica se explica tan sólo en un escritor preocupado por que el lector esté bien orientado en el ingente material que se le ofrece y no pierda de vista el carácter monográficamente asiático del libro, así como la marginalidad de los elementos no asiáticos. El motivo de la consulta del oráculo (II 14.3), donde podríamos suponer una influencia del modelo de Alejandro (así como en la secuencia Egipto-Bactra), tiene sin embargo un papel narrativo «prospectivo», interno a la historia de Semíramis (que no tiene la consulta de Alejandro, que versa sobre los orígenes) por referencia a los acontecimientos del final de la vida de Semíramis y su divinización (II 20) que en cualquier caso no es debida a sus beneficios a la humanidad o conquistas. El epílogo de Diodoro a la historia de Semíramis, «tras haber reinado sobre toda Asia excepto la India» (II 20.2), es indicativo tanto de la limitación de este personaje al espacio asiático, como de la imagen de Asia que tiene Diodoro. Esta independencia genérica con respecto al modelo de Alejandro puede, si se quiere, añadirse a la cuenta de los elementos ctesianos mantenidos por Diodoro, pero, habida cuenta de que el cuadro es coherente con pasajes que no pueden

52 Sobre la posibilidad de que el cuadro de las conquistas de Semíramis haya sido rehecho sobre el modelo de Alejandro, sobre todo en lo que toca a la conquista de la India (II 16-18), es prudentemente reservado Drews, The Greek Accounts of Eastern History, Cambridge (Mass.), 1973, p. 195. Cf. Lens, «Libro II...», cit., p.343, nota 25. En realidad, tal vez el paralelo más adecuado no sea la campaña de Alejandro, en la India sino la expedición de Darío a Escitia que conocemos por el sin par relato de Heródoto IV 5-144, donde encontramos de manera recurrente los temas del engaño, los insultos, la inversión, el valor simbólico del río como frontera natural, entre otros.

53 II 16.1 .

EMERITA. Revista de Lingüística y Filología Clásica (EM) - LXV 1, 1997, pp. 17-40 
J. Lens Tuero - J. CAMpos DarocA - La geografía de Asia en el libro II de la Biblioteca Histórica de Diodoro de Sicilia

remontar a Ctesias, hay que contar en igual o mayor medida con la voluntad de Diodoro de mantener en la narración una cierta «coherencia histórica» de acuerdo con un concepto específico de la historia de Asia, actuación que le permite salvaguardar la individualidad de los personajes, sobre todo uno tan sugerente como es el de Semíramis, y nos advierte contra una tipificación excesiva en el estudio de la Biblioteca ${ }^{54}$. Es mejor suponer que Diodoro ha uniformado las figuras del libro II de acuerdo con una imagen prototípica del «gobernante asiático», derivada de la tradición griega sobre este tema (con Heródoto y, sobre todo, Ctesias a la cabeza), en la que los rasgos recurrentes vienen a ser: a) su actividad conquistadora; b) sus grandes construcciones (cuyo valor es esencialmente monumental y sólo en segundo término evergético); y c) un componente de arbitrariedad y hasta crueldad en su comportamiento regio. A estos rasgos dominantes se subordinan los que puedan añadirse por la convergencia con otra imagen igualmente prototípica, la del monarca héroe conquistador y benefactor que alcanza honores divinos. Pero obsérverse que ambas imágenes son concurrentes sólo parcialmente, y en última instancia irreductibles. Pues si bien coinciden en los elementos de la conquista y la civilización, difieren radicalmente en lo que toca a la valoración moral, que en el caso de los monarcas asiáticos es o negativa o, en todo caso, poco ejemplar ${ }^{55}$, donde juegan poco o nulo papel las virtudes filantrópicas tan importantes en la Biblioteca de Diodoro, especialmente en lo que toca al tema de los imperios ${ }^{56}$. Es ciertamente visible la tendencia de Diodoro a aproximar ambos modelos, pero debemos también reconocer a Diodoro la capacidad de mantener la especificidad del monarca asiático, de la que no es ajeno cierto sentido histórico ${ }^{57}$.

\footnotetext{
54 Es significativa la voluntad de Diodoro de buscar paralelos a la historia de Asia en la historia de la expansión romana: guerra contra Aníbal (II 5.7) y guerra contra Perseo (17.3).

55 Crueldad de Nino II 1.7; 18.5. Semíramis II 13.4.

56 El tópico de la conducta humanitaria empieza a jugar un papel en la historia meda con Arbaces (II 28,4; 7), mientras que es prácticamente inexistente en las conquistas de Nino (tan sólo en II 2.8 se nos dice que se comportó con magnanimidad, pero los párrafos inmediatamente anterior y siguiente muestran a las claras lo excepcional de este comportamiento) y en las de Semíramis.

57 Bien evidente en II 27.1.
}

EMERITA. Revista de Lingüística y Filología Clásica (EM) - LXV 1, 1997, pp. 17-40 
J. Lens Tuero - J. CAMpos DarocA - La geografía de Asia en el libro II de la Biblioteca Histórica de Diodoro de Sicilia

Una inteligente indicación de Bigwood sobre la labor diodorea se puede leer igualmente en este sentido ${ }^{58}$. En II 1.5-6 y II 16.3-4 introduce Diodoro sendas referencias a Arabia y la India que concuerdan notablemente con las secciones específicas del libro dedicadas a estas regiones (II 48.1-5 y II 35.336.4). Para un autor como Krumbholz eran estas intervenciones de Diodoro posteriores a la composición de las secciones correspondientes ${ }^{59}$. Pero, siguiendo a Bigwood, podemos considerar estos pasajes como indicios de un plan de Diodoro que abarca el conjunto del libro II, el de incluir en su monografía de Asia las secciones correspondientes a estas dos regiones tan representativas de su idiosincrasia, secciones que habrían sido adelantadas de acuerdo con la práctica diodorea de intensificar la cohesión textual de su Biblioteca por medio de una densa red de referencias internas a la que ya hemos aludido.

Así pues, la sección histórica del libro II de Diodoro da una primera pauta que permite cohesionar el grueso de los materiales del mismo en función de su pertinencia al tema de Asia como espacio de poder, en el que se define un núcleo invariable de dominio, en cuyo centro urbanístico se resuelven los problemas de sucesión de toda Asia ${ }^{60}$, y una frontera especialmente fluida, y donde se define la cualidad del gobernante por la amplitud de sus esfuerzos expansivos. Los pueblos de las márgenes se definen por su relativa independencia, que se incrementa conforme avanzamos hacia los límites septentrional y meridional.

En este punto la definición «política» de Asia, que es la dominante a lo largo del libro, se complementa con una estrictamente geográfico-climática que resume y sintetiza el saber «científico» de su época, según el cual el que Asia comprende el mundo no griego que se extiende hacia oriente, con límites más definidos hacia el oeste en el Tanais y Nilo pero enormemente imprecisos en el resto de los puntos. Recordemos que esta definición «natural»

58 Art. cit., pp. 206-7.

59 «Wiederholungen bei Diodor» RhM 44, 1889, pp. 291 ss.

60 La ciudad de Babilonia, descrita con morosidad por Diodoro (II 7-10), reproduce con su arquitectura en círculos concéntricos, la imagen de Asia que detectamos en el conjunto del libro; cf. J.M. Bigwood, «Ctesias Description of Babylon», AJAncHist 3., 1978, pp. 32-52. 
J. Lens TUero - J. CAMPos DARocA - La geografía de Asia en el libro II de la Biblioteca Histórica de Diodoro de Sicilia

pone en funcionamiento una segunda nota temática: la productividad y variedad de oriente conectada a condiciones climáticas excepcionales.

Desde esta óptica geográfica, Diodoro articula su libro de modo que, dentro de esa orientación cualitativa dominante hacia el este, cubra el espacio conocido. Esto queda bien explícito cuando, despues del capítulo dedicado a los hiperbóreos, que agota el espacio conocido por el norte, nos propone «trasladarnos a la otra parte de Asia» (II 48.1), para emprender la descripción de la región sur hasta las islas del Sol. Las articulaciones textuales dejan ver la pertinencia que Diodoro observa en los diversos pueblos con respecto al tema central de Asia. Escitia y Arabia presentan una relación de contigüidad territorial, mientras que los pueblos «utópicos», con cuya localización concreta es más difícil comprometerse, muestran una motivación textual más 
J. Lens TUero - J. CAMPos DARocA - La geografía de Asia en el libro II de la Biblioteca Histórica de Diodoro de Sicilia

genérica ${ }^{61}$. De hecho presentan carácter de «apéndices» ${ }^{62}$, lo que se corresponde bien con su independencia política y aislamiento típicamente isleño.

Isla del norte: Hiperbóreos (47)

Escitas (43-44) y Amazonas (45-46).

Asiria/Media (1-34) - India (35-42).

61 Sartori insiste en la localización geográfica de las utopías por parte de Diodoro como argumento para quitar precisamente valor utópico a los relatos de los hiperbóreos y las islas del Sol; cf. «Storia...», art. cit., pp. 512-13. El hecho de que estos lugares sean localizables en la representación geográfica diodorea no resta carácter utópico al conjunto, marcado claramente por su especial aislamiento y consecuente inaccesibilidad. Toda la ficción utópica desde el siglo IV se construye sobre el juego de verosimilitudes que permiten los nuevos viajes, de Piteas o Eudoxo de Cízico por mencionar los que se han puesto en correspondencia con Hecateo y Yambulo. Por otro lado, la localización de ambas islas al norte y al sur respectivamente es tan genérica como la de Meropis de Teopompo o la Atlántida platónica, y contrasta con la contigüidad territorial de las demás regiones asiáticas (cf. II 35.1, 43.1, 48.1). La breve historia amazónica tiene, por su parte, una vinculación estrictamente «textual» (II 44.3). Sobre la literatura utópica ha habido recientemente abundantes trabajos, entre los que podemos destacar los del reconocido especialista en el tema L. Bertelli, «Itinerari dell'utopia greca: dalla città ideale alla isole felici», en R. Ugliore (ed.) La città ideale nella tradizione classica e biblico-cristiana, Turín, 1986, pp. 35-56; id., «L'utopia», en G. Cambiano, L. Canfora y D. Lanza (edd.), Lo spazio letterario della Grecia antica, vol.I: La produzione e la circolazione del testo, tomo I: La polis, Roma, 1991, pp. 493-524; en español tenemos los trabajos recientes de H. F. Bauzá, El imaginario clásico. Edad de Oro, Utopía y Arcadia, Santiago de Compostela, 1993, y el extenso y documentado trabajo de F. J. Gómez Espelosín «Tierras fabulosas del imaginario griego» en el colectivo Tierras fabulosas de la Antigüedad, Alcalá de Henares, 1994, pp. 103-303. Importantes precisiones metodológicas en M. Brioso, «Geografía mítica de la Grecia Antigua», Philologia Hispalensis 8, 1993, pp. 193-213.

62 La descripción de los hiperbóreos tiene el carácter de sección «mitológica» de Asia (II 47.1), así como las islas del sol son un apéndice a la sección paradoxográfica (II 55.1). Se debe también prestar atención al hecho de que ambas secciones «utópicas» presentan características enunciativas peculiares: en los dos casos nos encontramos con una delegación explícita de la palabra por parte de Diodoro. Pese a que en el caso de los hiperbóreos esta delegación aparece menos marcada, por lo que sabemos de Hecateo de Abdera podemos avanzar que su escrito sobre los hiperbóreos se construía también como un relato de viajes, anclado por tanto en la experiencia personal y en la enunciación en primera persona (siguiendo en esto una ya vieja tradición que remonta a Aristeas de Proconeso); este elemento clave de la narración hecataica habría desaparecido, como también en el caso de Evémero, según Jacoby, en el proceso de epitomización; cf. Jacoby, FGrHist, Kommentar zu 264 F 7, Leiden, 1964, p. 53.

EMERITA. Revista de Lingüística y Filología Clásica (EM) - LXV 1, 1997, pp. 17-40 
J. Lens Tuero - J. CAMpos DarocA - La geografía de Asia en el libro II de la Biblioteca Histórica de Diodoro de Sicilia

Arabia (48-54).

Islas del sur: relato de Yambulo (55-60).s

IV

Paralelamente a su función indirectamente geográfica, en un lógos etnográfico dedicado a un continente en el que la norma es la diversidad etnográfica, la historia asirio-meda viene a desempeñar el papel de material histórico tout court, homólogo de la historia faraónica en el libro I. Son notables las semejanzas entre la historia faraónica y la asirio-meda, sin duda debidas a que ambas están centradas en la figura del monarca, punto en el que concuerdan con las formas historiográficas dominantes en oriente próximo ${ }^{63}$.

Una vez más, guiado por las exigencias estructurales y temáticas de la Biblioteca, Diodoro ha operado un proceso que nos atrevemos a denominar de «emblematización», especialmente manifiesto en la parte asirio-meda. En el ámbito histórico, esta emblematización se pone de manifiesto en que las largas listas de reyes quedan simplificadas en un número muy pequeño de soberanos, en los que se representan los momentos clave de la historia de los imperios ${ }^{64}$. Especialmente paradigmático a este respecto viene a ser el caso de la monarquía asiria, reducida a la pareja de Nino y Semíramis, consolidadora del imperio, y a las figuras de Ninias y Sardanápalo, que causan su pérdida. La fuerte simetría ente las dos secciones de la historia asiria es clara: al instinto expansivo de Nino y Semíramis corresponde la tendencia a la pasividad y la restricción al palacio de los dos últimos monarcas, siendo en esto Ninias fundador de una tendencia que Sardanápalo lleva al máximo.

En esta parte del libro II de la Biblioteca existe una profunda conexión entre la «emblematización» de la monarquía y la del territorio; a la significación de la figura del monarca y su familia corresponde la importancia cuantitativa y cualitativa que en el relato adquiere el palacio. A su vez, el inmenso y variado paisaje asiático parece no tener sentido más que para que el sobe-

${ }^{63}$ Cf. H. Cazelles, «Historiographies bibliques et prébibliques», Revue Biblique 98.4, 1991, pp. 490-2.

${ }^{64}$ Sobre esta característica de la historiografía griega de tema «oriental» cf. R. Drews. o. cit. 
J. Lens TUero - J. CAMPos DARocA - La geografía de Asia en el libro II de la Biblioteca Histórica de Diodoro de Sicilia

rano haga exhibición de su poder de transformación del medio físico mediante la realización de obras.

Constatamos, ante todo, que esta perspectiva regia tiene una consecuencia «geográfico-espacial», el interés por el entorno inmediato del monarca, la corte y el palacio, a partir del cual se extiende e irradia el orden al resto del dominio. Consecuencia de esta focalización en la figura del rey, que se expresa de manera privilegiada en sus monumentos, es la condición «urbana» o, mejor, «urbanística» de esta historiografía. La formación del imperio se define por los dos actos complementarios de la conquista y la fundación de una capital que organiza el espacio conquistado y, análogamente, la narración de la historia asiria se desarrolla entre ambos polos: extensión del imperio versus encierro en el palacio.

Hay una segunda consecuencia de orden temático. Los problemas históricos fundamentales vienen a ser los que tienen que ver con la sucesión y la legitimidad. Las intrigas de corte y las rivalidades vinculadas a la sucesión, la continuidad dinástica y su ruptura son tan importantes desde esta perspectiva historiográfica como exóticas y pintorescas resultaban para el mundo griego. Pero es claro que estos ámbitos de coincidencia no son únicamente el resultado de un influjo oriental ${ }^{65}$, sino que son también el resultado de un proceso de selección típico de la historiografía griega de tema oriental, que se manifiesta, en la reflexión histórica y política helenísticas, en el interés por los grandes conjuntos monumentales asociados a las grandes monarquías del próximo oriente, y en la selección de figuras emblemáticas de monarcas a partir de los intereses del público. Este proceso de «emblematización», en virtud del cual, en la secuencia de reyes, se verifica un proceso de selección a partir de un criterio axiológico tradicional, viene a producir interesantes y significativas coincidencias entre los reyes destacados por Diodoro y los que

${ }^{65}$ Existen interesantes coincidencias de motivos entre el relato de Diodoro (que sigue a Ctesias de cerca en este punto) y las variadas tradiciones de la historiografía mesopotámica y del cercano oriente. Es significativa en este sentido la importancia de los motivos proféticos en la sucesión de Semíramis (II 20) y, sobre todo, en la historia de la translatio imperii de Asiria a Media (II 24.1; 25.8; 26.9; cf. J. van Seters, In Search of History. Historiography in the Ancient World and the Origins of Biblical History, New Haven-London, 1983, pp. 96 ss; 303 ss.). La historia de Nino y Semíramis (II 6.9-10) tiene ciertas semejanzas con la de David y la mujer de Urías (2 Samuel 11).

EMERITA. Revista de Lingüística y Filología Clásica (EM) - LXV 1, 1997, pp. 17-40 
J. Lens TUero - J. CAMPos DARocA - La geografía de Asia en el libro II de la Biblioteca Histórica de Diodoro de Sicilia

protagonizan la literatura novelesca de la época que de modo progresivo vamos conociendo por los restos papiráceos ${ }^{66}$.

La historia asirio-meda constituye pues un primer factor de unidad a partir del cual se organizan los demás elementos en una dispersión progresiva que resulta en la segunda tónica del acorde asiático: la variedad. Pero esta variedad, insistimos, se encuentra controlada por el deseo de dar al conjunto de Asia la estructura de un logos cohesionado. Se verifica en este sentido una elemental especialización de contenidos por etnias, de modo que el conjunto constituye una presentación completa, dentro del espacio asiático, de la serie de tópicos que forman un logos etnográfico.

Es llamativo en este sentido la complementariedad de los logoi de la India y Arabia. Mientras que en el caso de la India se han eliminado prácticamente todos los mirabilia naturales, para concentrar la relación en los aspec-

${ }^{66}$ El descubrimiento de los fragmentos de la novela de Nino y Semíramis (P.Berol. 6926; PSI 1305; hay traducción española con breve introducción de Julia Mendoza en Quereas y Calírroe, Efesíacas. Fragmentos novelescos, Madrid, 1979, pp. 327-339) supuso, como se sabe, un cambio radical en nuestro conocimiento de la novela antigua. La comparación entre la versión Ctesias-Diodoro y los fragmentos de papiro en lo que toca a estos personajes novelescos la emprendió ya M. Braun, History and Romance in GraecoOriental Literature, Oxford, 1938, pp. 6 y ss. y fue seguida por B.E. Perry, The Ancient Romances. A Literary-Historical Account of Their Origins, Berkeley-Los Angeles, 1967, pp. 164-166, con interesantes conclusiones acerca de la naturaleza de las convenciones de la escritura histórica y la ficción literaria antigua; significativamente, ambos textos coinciden en los datos político-militares (campaña de Armenia, Diod. II 1.8; frag. B, para la que Braun o. cit., p. 12, postula diversos canales de transmisión; Egipto, Diod. II 2.3; frag. B3; no deja de tener interés la coincidencia entre los diecisiete años que Nino tarda en comletar sus conquistas según Diodoro (II 2.1) y los diecisiete años de edad de Nino en la novela (frag. AI)). Perry destaca el contraste del carácter de Nino, de déspota oriental a héroe de novela amorosa, comparación especialmente interesante para nosotros que hemos destacado más arriba el carácter poco «ideal» de las figuras de Nino y Semíramis en el relato de Diodoro. Los datos coincidentes disminuyen la probabilidad de que Ctesias sea la fuente exclusiva para la historia Asirio-Meda. En el caso de la figura de Sesóosis en Diodoro, el paralelo con los fragmentos papiráceos de Sesóncosis (POxy. 1826, 2466 trad. por Julia Mendoza, o. cit,. pp. 404-7, a los que habría que añadir el POxy. 3319, publicado pro S. West en el volumen 47, 1980) es mucho más estrecho; cf. J.N. O'Sullivan, «The Sesonchosis Romance», ZPE 56, 1984, pp. 39-44.

EMERITA. Revista de Lingüística y Filología Clásica (EM) - LXV 1, 1997, pp. 17-40 
J. Lens TUero - J. CAMPos DARocA - La geografía de Asia en el libro II de la Biblioteca Histórica de Diodoro de Sicilia

tos económico y social-institucional, en Arabia encontramos el caso inverso. La opción de Diodoro es en este caso especialmente clara, dado que podía disponer de un cuadro tan fantástico de la India como el de Ctesias, ejemplo sin par de fabulación etnográfica sobre este tema ${ }^{67}$. La India de Megástenes ${ }^{68}$ tiene, por contra, un notable parecido con el egipcio hecataico como paradigma de la excelencia social que entra sin paliativos en el ámbito de la utopía política, y aporta al conjunto del logos asiático la dimensión institucional que no podían cubrir ninguno de los demás pueblos ${ }^{69}$.

La sección dedicada a Arabia reviste un especial interés tanto por los contenidos como por la fructífera comparación que permite con otros autores contemporáneos. Se trata además de una sección que, en contraste con la dedicada a la India, ha atraído poca atención de los estudiosos, excepto por la circunstancia de constituir un pasaje clave para la reconstrucción de la obra y el pensamiento de un autor como Posidonio ${ }^{70}$. En efecto, la mención

${ }^{67}$ Del que sin embargo toma algunos elementos; cf. Lens, «Introducción ...», cit., pp. 295-7. En general, sobre la India en Ctesias, cf. los trabajos de K. Karttunen, India in Greek Literature, Helsinki, 1989, pp. 80-85.

${ }_{68}$ Sobre Megástenes, sus modelos literarios literarios e intereses propagandísticos, $\mathrm{cf}$. A. Zambrini, «Idealizzazione di una terra: Etnografia e propaganda negli Indiká di Megastene», en Modes de contacts et processus de transformation dans les sociétés anciennes (Actes du colloque de Cortone, 24-30 mai 1981), Pisa-Roma 1983, pp. 105-18, esp. pp. 113-4: «Anzi l'opera di Ctesia mostra la differenza profonda tra un tipo d'interesse per l'India tendente al 'mostruoso' ed al fantastico, con il conseguente risultato di una raccolta di dati incredibili non coordinati tra di loro in una coerente e logica struttura letteraria, ed un tipo di interesse como quello megastenico, finalizzato alla creazione di un cuadro generale logicamente omogeneo, in cui tutte le singolare notizie contribuiscono alla idealità globale dell'India e della popolazione que vi abita». Es posible con todo descubrir cierta coherencia en la India de Ctesias a partir de otros criterios de identidad étnica y política, como ha puesto de manifiesto J. Campos, Experiencias del lenguaje en las 'Historias' de Heródoto, Almería, 1992, pp. 143-152.

${ }^{69}$ Zambrini ha desarrollado en dos extensos y documentados artículos la idea de que Megástenes utiliza el modelo egipcio de Hecateo de Abdera para proponer una imagen idealizada de la India que refleja los intereses integradores del joven y problemático reino seléucida («Gli Indiká di Megastene I», ASNP 12 (1982), pp. 71-149, II, pp. 781-853), relación acertada pero que debe matizarse en algunos aspectos que atañen precisamente a la redacción de Diodoro; cf. J.Lens - J. Campos, art. cit., p. 139, n.6.

70 Atribuido a Agatárquides por Schwartz, art. cit., coll. 672-3, Reinhardt (Poseidonios, Munich, 1921, pp. 128-135) reivindicó a Posidonio como fuente, y como tal aparece en los 
J. Lens Tuero - J. CAMpos DarocA - La geografía de Asia en el libro II de la Biblioteca Histórica de Diodoro de Sicilia

reiterada por parte de Diodoro al acción solar como factor explicativo de la peculiar naturaleza de los productos de Arabia (y en general de toda la zona sur de la tierra) remite, según Reinhardt y los que en esto lo siguen, a la for-

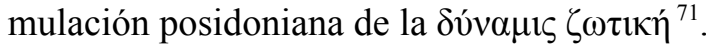

Con la descripción de Arabia Diodoro desplaza la descripción al sur, que complementa la relación ordenada de la parte norte de Asia. Siguiendo el criterio dominante en esta parte de la Biblioteca, la presentación de Arabia pretende seguir los criterios geográficos de articulación del espacio; el resultado es sin embargo de una confusión notable. Diodoro comienza situando Arabia de manera un tanto vaga entre Egipto y Siria y prosigue describiendo la parte oriental, que identifica con el territorio de los Nabateos. La descripción de este pueblo se organiza, desde el punto de vista propiamente etnográfico, en torno a un tema predilecto de Diodoro: el de la independencia política de los pueblos marginales, al que se añaden otras noticias de carácter más paradoxográfico, como la producción de asfalto o de balsamo. A continua-

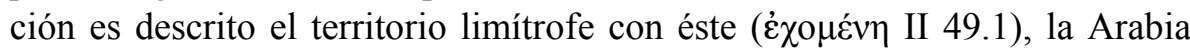
Feliz, sin especificar la orientación que se sigue, aunque el extenso pasaje hace ver que se trata del extremo sur. Los aromas centran, como era de esperar, el interés de Diodoro ${ }^{72}$. Pero conforme progresa la descripción el tópico

fragmentos recopilados por W. Theiler (Poseidonios. Die Fragmente, I, Berlín, 1982, F 78 [= FGrHist F 114]); excluído naturalmente en la de Edelstein-Kidd, Poseidonius, Cambridge, 1973-1986, quienes consideran la atribución de Reinhardt más que dudosa. J. Malitz, Die Historien des Poseidonios, Munich, 1983, pp. 266-71, asigna la sección diodorea sobre Arabia a las Historias de Posidonio en su excurso geográfico-etnográfico sobre la historia de los seleúcidas, aunque reconoce cierta discontinuidad entre el cuadro de Arabia y la tónica más bien pragmática de las Historias. Posidonio habría tenido como modelo la obra de Agatárquides Sobre el Mar Rojo.

${ }^{71}$ II 51.3 y Cicerón, De natura deorum, II 24; cf. K. Reinhardt. «Poseidonios» RE XXII.1, 1953, col. 648.

72 Sobre Arabia y los aromas, cf. M. Detienne, Los jardines de Adonis. La mitología de los aromas, Madrid, 1983, pp. 57-97, y A. Lallemand, «Le parfum comme signe fabuleux dans les pays mythiques», en F. Jouan y B. Deforgue (edd.) Peuples et pays mythiques, París, 1988, pp. 73-90, esp. pp. 81-3; véase recientemente el libro de V. Domínguez García, Los dioses de la ruta de los aromas. Un estudio de Evémero de Mesene, Oviedo, 1994. Una primera aproximación a los historiadores griegos autores de Arabiká en J. Campos Daroca y J.L. López Cruces, «Fragmentos de historiadores griegos de Arabia», en Homenaje a la profesora Elena Pezzi, Granada, 1992, pp. 283-298.

EMERITA. Revista de Lingüística y Filología Clásica (EM) - LXV 1, 1997, pp. 17-40 
J. Lens Tuero - J. CAMpos DarocA - La geografía de Asia en el libro II de la Biblioteca Histórica de Diodoro de Sicilia

se va ampliando hasta abarcar el conjunto de Asia como productora de formas excepcionales y maravillosas: Babilonia, Siria, India y hasta las partes orientales de Africa, cuya pertenencia a Asia fue siempre cuestión discutida, se unifican por la acción vivificadora del sol oriental. Diodoro complementa las fabulosas noticias con una comparación de conjunto con otras zonas del mundo en las que se dan los mismo productos pero con una diferencia cualitativa apreciable (II 53.5-7).

Obligado por el carácter errático que ha tomado el discurso Diodoro cierra la sección con un cuadro de conjunto de Arabia ( $\tau \hat{\eta} \varsigma$ ö $\lambda \eta \varsigma^{\prime}$ 'A $\alpha \beta \beta_{\alpha} \alpha \varsigma$ II 54.1) en el que distingue: a) Arabia Feliz, hacia el sur ( $\left.\pi \rho o_{\varsigma} \mu \varepsilon \sigma \eta \mu \beta \rho i ́ \alpha v\right)$; b)

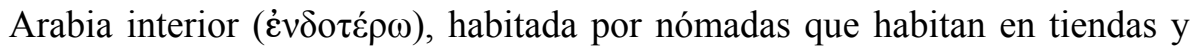
crían ganado; c) una zona «intermedia» entre las dos anteriores ( $\dot{\varepsilon} \vee \mu \varepsilon \dot{\varepsilon} \sigma \omega)$, desierta y sin agua, que Diodoro parece hacer corresponder con la Nabatea; d) las zonas de Arabia hacia occidente ( $\pi \rho o ́ \varsigma \delta v \sigma \mu \alpha ́ s)$, desérticas, atravesadas por caravanas; e) Arabia que limita con Siria, habitada por agricultores y

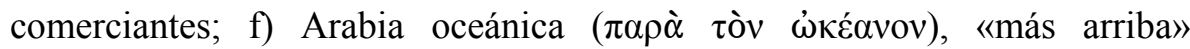

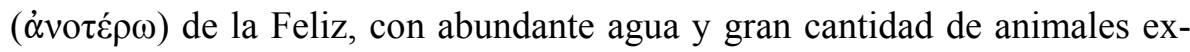
traños.

En el texto de Diodoro conviven, pues, dos presentaciones geográficas de Arabia que varían en detalle: a) la primera de carácter global que delimita Arabia por los territorios vecinos de Egipto y Siria y distingue esencialmente dos regiones: la desértica, país de los Nabateos, y la del sur, Arabia feliz; b) la segunda, que pretende presentar un cuadro más detallado y completo de las regiones de Arabia, delimitándola por todas sus partes.

Uno se siente tentado a cargar sobre la mediocre inteligencia de Diodoro la confusión de todo el pasaje, pero la comparación con la literatura enciclopédica de su tiempo presenta paralelismos significativos. La división bipartita de Arabia en Arabia desértica y Arabia Feliz según una orientación global hacia el sur es, sencillamente, la vigente en época de Diodoro; ahora bien, cada autor intenta detallar este cuadro tan genérico de acuerdo con informaciones complementarias y guiado por intereses específicos ${ }^{73}$. Un reciente

73 A. Dihle, «Plinius und die geographische Wissenschaft in der römischen Kaiserzeit», en Tecnologia, economia e societè nel mondo romano, Como 1980, pp. 121-37 (incluído en Antike ..., pp. 174-190), ha puesto de relieve, comparando las noticias sobre la India de 
J. Lens TUero - J. CAMPos DARocA - La geografía de Asia en el libro II de la Biblioteca Histórica de Diodoro de Sicilia

trabajo de Macadam pone de manifiesto la incongruencia que caracteriza la presentación de Arabia en autores como Estrabón, Plinio o Ptolomeo ${ }^{74}$. Para el caso de Plinio es interesante constatar que nos encontramos con un desconcierto semejante cuando intentamos llegar a una imagen coherente de Arabia a aprtir de las diversas noticias que nos proporciona. En la sección geográfica de la Historia Natural reciben el nombre de Arabia hasta cuatro áreas distintas: en primer lugar el territorio que se extiende entre Pelusio y el Mar Rojo, habitada por muchas tribus entre las que destacan Scenitae y Nabateos y separa Egipto de Judea; la Arabia feliz y productora de aromas, en la otra orilla del mar Rojo (V 12,65); la Arabia oriental poblada por nómadas (V 15,72); y la Arabia junto al Eufrates (V 20,85). Pero más adelante podemos ver que, cuando Plinio la trata en general, el cuadro de Arabia se remite a una división bipartita (VI 142-162): una noroccidental en la que habitan Nabateos y Escenitas y otra sudoriental, el país de los aromas. Separadas ambas por una línea imaginaria entre Acaba y Carax en el golfo pérsico. Análogo es el caso de Estrabón, que muestra con Plinio significativas coincidencias de detalle. Estrabón ofrece de nuevo una visión en conjunto bipartita norte - nómadas / sur - aromas dentro de la presentación global del ecumene (II 5,32), pero en la parte dedicada a Arabia en el libro XVI nos ofrece un cuadro más detallado, que recuerda bastante al de Diodoro. Distingue en el norte de acuerdo con la mayor proximidad a la frontera del Eufrates, entre árabes y nómadas; entre los árabes nómadas del norte y la Arabia Feliz al sur, se extiende un extenso y seco desierto. Todavía en XVI 4.21 introduce Estrabón un tercer cuadro de Arabia que desde luego no clarifica las cosas ${ }^{75}$.

Estrabón y Plinio, una práctica fundamental de la literatura geográfica del siglo I, la de atenerse para la presentación de conjunto a los autores «clásicos», esto es, reconocidos como autoridad en la formación literaria, (Eratóstenes en este caso), complementados, en todo caso, con noticias más recientes que no alteran el cuadro general aunque, en ocasiones, sean completamente incompatibles.

74 «Strabo, Pliny the Elder and Ptolemy of Alexandria: three views of Ancient Arabia and its peoples», en T. Fahd (ed.), L'Arabie préislamique et son environment historique et culturel, Leiden, 1989, pp. 289-320.

75 El confuso cuadro de Didoro remite pues a la representación vigente de un espacio en el que se dejan ver con especial claridad las limitaciones de la geografía antigua, estudiadas magistralmente por P. Janni, La mappa el il periplo. Cartografia antica e spazio odologico, Roma, 1984. Arabia es, más que cualquier otra, una tierra en la que los diversos accesos para 
J. Lens Tuero - J. CAMpos DarocA - La geografía de Asia en el libro II de la Biblioteca Histórica de Diodoro de Sicilia

Pero está claro que a Diodoro le interesan menos aportar un cuadro completo de las regiones y etnias que pueblan Arabia que construir un cuadro de la misma que cumpla su función en el conjunto del libro II. Las distinciones propiamente geográficas se distribuyen en dos secciones que sirven de marco al tema realmente importante, la relación de los mirabilia naturales que produce esta región de Asia en comparación con otras regiones. Es significativo que en este desarrollo paradoxográfico las indicaciones geográficas sean claramente erráticas, distribuyéndose indistintamente por toda la región de Arabia e, incluso, el conjunto Asia. Diodoro potencia, pues, el factor geográfico común a Arabia, su situación al sur del mundo habitado, y los efectos de esta localización en la generación de mirabilia, superando las diferencias geográficas parciales en el interior de ese cuadro. El elemento propiamente etnográfico está fuertemente restringido a las escasas indicaciones sobre géneros de vida, nómada o sedentario, con excepción de lo que se vincula a la producción de aromas o, significativamente, al asunto estratégico de los nabateos (recurrente en Diodoro). El contraste con Estrabón es significativo. Mientras que en éste autor se consideran los aromas desde el punto de vista económico-militar y moral, con una formulación casi paralela en ocasiones ${ }^{76}$, en Diodoro está completamente ausente este factor ${ }^{77}$; reducidos a $p a-$ radoxa, los aromas dan paso a auténticas maravillas como los animales biformes y las piedras preciosas. Arabia se convierte así en la sección paradoxográfica del libro II y su interés es, casi exclusivamente, el de sus productos como emblema de la fabulosa fertilidad de Asia.

JESÚS LENS TUERO

JAVIER CAMPOS DAROCA

el viajero de Occidente determinan imágenes diferentes, subsumidas bajo un nombre, pero sin que se sienta la necesidad de sistematizarlas. En Diodoro (cf. Janni, o. cit., p. 105), a Arabia se llega desde Egipto para tomar el camino de Siria o el del país de los aromas; el resto es tierra transitable sólo para los nómadas y sus caravanas.

76 Cf. Estrabón, XVI 4.22 y Plinio NH VI 161.

77 El propio Diodoro ofrece un ilustrativo contraste en el libro III, donde al hilo de la descripción de los pueblos del Mar Eritreo encontramos una presentación de los Sabeos dominada por el tópico moral del equilibrio tan caro a Diodoro (46-7).

EMERITA. Revista de Lingüística y Filología Clásica (EM) - LXV 1, 1997, pp. 17-40 